\author{
Л.В. Куркина \\ Институт русского языка \\ им. В.В. Виноградова РАН \\ (Россия, Москва) \\ lyukurkina@rambler.ru
}

\title{
К РЕКОНСТРУКЦИИ ЭТИМОЛОГИЧЕСКОГО ГНЕЗДА С ОСНОВОЙ *TELP-
}

В работе предложен опыт восстановления генетических связей рассеянных по славянским языкам образований с основой *telp-. Отправной точкой поисков стали рус. диал. телепать, телепень, которые, по мысли В.Н. Топорова, отражают одну из ступеней морфонологического ряда *telp-: *tolp-: *tъlp- (cp. хетт. Telepinuš, бог плодородия, лув. taluppi 'ком', 'глыба') с исходными значениями, унаследованными из сферы пчеловодства, - 'хаотичное, беспорядочное движение' и 'нечто сбитое в ком'. Предложены аргументы в пользу сближения по формальным и семантическим основаниям русских диалектизмов с польск. ttopić się 'толпиться, проталкиваться', слав. *tъlpa. В предположительной форме ставится вопрос о возможности отнесения к этой группе слов рус. диал. толопа 'звериная тропа', для которого вне этого контекста предполагается заимствование.

Ключевые слова: этимология, морфонологические отношения, структура основы, реконструкция семантики.

В этимологии весьма существенна проблема распада и восстановления этимологического гнезда. В силу разных причин (изменение фонетического облика слова, удаленность морфонологических вариантов и т. п.) происходит ослабление родственных связей и разрушение этимологического гнезда, сопровождающееся расщеплением изначально генетически единого целого на отдельные фрагменты, которые начинают функционировать самостоятельно, образуя свою систему парадигматических, семантических связей внутри словаря. Распаду изначальных связей способствует и притяжение со стороны синонимичных лексем, образующих лексико-семантическое поле, подключение к активным словообразовательным моделям и т. п. Задача состоит в том, чтобы по сохранившимся остаточным явлениям с опорой на структуру, семантику попытаться восстановить утраченные связи, определить место изолированных образований в исходной для него системе. Ключевая 
роль в решении этого вопроса принадлежит материалу. С выходом в свет новых диалектных словарей, существенно расширяющих материальную базу исследований, появляется возможность с применением комплексной методики в более широком контексте, русском и шире - славянском, соотнести явления, удаленные и на первый взгляд никак не связанные между собой.

Предметом нашего рассмотрения станет ограниченная вост.-слав. ареалом группа слов, в которой наибольшую активность обнаруживают рус. телепень, телепаться. С привлечением диалектных источников в исследованиях найдем подробное описание состава и семантики слов, так или иначе связанных с гл. телепаться [Шахматов 1902: 360-361; Топоров 1985: 12], и это позволяет нам свести описание семантики к определению семантических центров, вокруг которых группируется все многообразие значений этих образований. Как показывают исследования, глагольная семантика сводится к реализации общего значения, которое, по В.Н. Топорову, может быть определено как 'неупорядоченное, хаотическое, разнонаправленное движение': рус. диал. телепаться 'болтаться, мотаться, висеть и качаться' [Даль² IV: 396], укр. теле́nати 'трясти, болтать, тихо идти', 'идти медленно, шлепать', ‘жадно есть', карп. теле́патися 'тащиться' [Гринченко 4: 252], закарп. telepaty ‘трясти, колебать’ [Балецкий 188], блр. цุеляпа́ųь 'болтать, мотать’ [Блр.-русск.], диал. тэлепа́ти экспр. 'идти с медленно, с трудом’ (Тур. сл. 5: 133) и т.д. Общим для именных образований является значение 'нечто плотное, толстое, неповоротливое, отличающееся большими размерами (человек, ребенок, животное, кусок дерева, металла и под.)’ [Топоров 1975: 12]: ср. рус. диал. телепе́нь 'дородный ребенок', те́лепень 'толстяк', теле́nа и телёпа 'о бестолковом человеке’ (волог.), ‘о несговорчивом, неуступчивом, непокладистом человеке’ (новг.), 'о вялом, нерасторопном, неуклюжем человеке' (новг.), 'о беспутном, ветреном человеке' (Бурят. ССР) [СРНГ 43: 349], телепня ‘месиво из пищевых отходов’ (Сл. Сред. Урала VI: 91) и т. п., укр. те́лепень карп. 'то, что болтается’, 'колокольный язык’ [Балецкий 189], 'неповоротливый, медлительный человек’ [ЕСУМ 5: 539], блр. цุеляпе́нь 'неуклюжий человек, толстяк' [Блр.-рус.] и т. п.

Традиционно в этимологической литературе эти образования с широким разбросом значений относят к разряду звукоподражаний [ср. Фасмер IV: 38-39; ЕСУМ 5: 539]. И такое объяснение вполне допустимо по отношению лишь к какой-то части образований. Однако в целом природа образований остается до конца не выясненной, особенно если принять во внимание, что в составе глагольных и именных образований присутствуют не только звукоподражания (ср. укр. межд. meле́n, выражающее момент падения, особенно во что-л. жидкое, теле́nати 'шлепать', 'жадно есть', рус. вариант тилипаться и т. п.), но и продолжения полноценного славянского апеллатива. Вероятно, в силу разных причин произошло сближение, слияние и поглощение звукоподражанием какой-то части полноценных слов, и как следствие - размылись границы разных по происхождению образований, и вся группа в целом стала восприниматься как неясная, звукоописательная по своей природе. Следует заметить, что вывод о звукоподражательном происхождении рус. телепать, телепень и т. п. ориентирует на общий, единый подход 
к характеристике названных слов и исключает из рассмотрения все другие аспекты, связанные со структурой и семантикой слова.

Как показывают другие опыты объяснения русских слов, некоторые неясности связаны с пониманием структуры, морфемного состава этих образований. В «Этимологическом словаре словенского языка» рус. телепень соотносится с параллельными образованиями в словенском языке: cp. telébiti 'вызвать падение, ударить', telébniti 'плюхнуть; плюхнуться, свалиться, упасть', telébati 'падать, плюхать, с силой ударять', устар. 'неловко, неуклюже ходить; летать' (ср. čmrlj teleba od cveta do cveta), краньск. teléba 'большой кусок (напр. хлеба)', прил. telében, telébast 'неловкий, неуклюжий' и т. п. [Plet.' II: 653], с.-хорв. диал. telébati 'хлопать, ударять', telèbiti 'пропасть' [Snoj in: Bezlaj IV: 164], разг. зателѐбати се 'сильно, неразумно влюбиться', ‘уставиться, смотреть, не отрывая глаз' [РСКНJ VI: 463], далее рус. диал. теле́бить 'тихо, медленно идти' (кур., орл.), телебо́нить 'звонить в колокола', 'красть, воровать', телебо́ниться 'пить для легкого опьянения' [СРНГ 43: 342], далее с другими расширениями стелебе́сить 'украсть что-л.' (сиб.), стелеляшить 'стащить, украсть что-л.' (арх., волог., костр.) [СРНГ 41: 125] и т. п. Из этого следует выделение в рус телепень двух морфем - корень тел- + непродуктивный суф. -еn, который усиливает экспрессивную окраску слова (ср. мазать и мазепа). M. Сной обратил внимание на параллельную форму в лит. стар. telêpyti 'говорить' (<‘толочь, бить'), которое вместе с приведенными образованиями подводит к восстановлению исходного *tel- ‘бить, толочь', широко представленного с расширителем - $k$ в продолжениях праслав. *telkt’i, ср. параллельно *tel-ež-> лит. telêžyti 'сильно толочь', telžti ‘с грохотом, шумом бросить, кинуть', 'бить, колотить' [Fraenkel 1078]. Сам факт соотнесения близких по звучанию слов в русском и словенском языках и предположение о возможной однотипной структуре этих образований заслуживает внимания. Однако не исключено альтернативное понимание, основанное на допущении независимого, параллельного развития образований с общей основой в двух удаленных друг от друга ареалах.

Новые перспективы открывает предложенное В.Н. Топоровым объяснение рус. телепать в широком культурно-историческом и индоевропейском контексте [Топоров 1972: 78-81; Он же 1975: 3-49]. Исследуя рус. телепать(ся) на материале народного творчества, в контексте восстанавливаемой архаической пчеловодческой ритуальной песни, привлекает в плане сравнения название 'исчезающего и возвращающегося божества плодородия’ в хетт. Telepinuš, хатт. Talipinu, Talipunu, далее лув. taluppi 'ком', 'глыба' и связанное с этим миграционным термином одно из и.е. названий крота - лат. talpa [Гамкрелидзе, Иванов II: 532], В. Н. Топоров приходит к важному выводу, согласно которому это образование, изначально обозначавшее разнонаправленное, неупорядоченное движение, процесс сбивания пчел в рой при образовании нового роя, в очень стертом и видоизмененном виде отражает унаследованный из индоевропейской эпохи термин пчеловодства. В качестве примера приводится детская песня «Тень, тень, потетень ...; толпа пчел, пчелы толпятся, телепаются ...» лит. bités talpinamos avilyje, отмечая, что в формуле Тень, тень, потетень ! может содержаться анаграмма табуизированного названия 
телепень (ср. особенно плетень - телепень) [Топоров 1975: 25, прим. 62]. В связи с этим В.Н. Топоров далее пишет: «Некогда телепень, телепаться могли употребляться при описании процесса сбивания пчел в ком, в плотно прижатую друг к другу массу, отличающуюся хаотическим, слабо выраженным движением или процесса образования пчелиного роя, который постоянно приходит в движение» (Топоров 1972: 78). С учетом того, что пчеловодство пришло через Кавказ и через островную и материковую Грецию из Малой Азии, В.Н. Топоров проводит идею о возможной связи древнего вост.-слав. термина пчеловодства телепень с малоазиатским telepin-, средиземноморским talp(in)-, балт. telp-/ talp(in), а на ностратическом уровне допускает связь этого термина с др.-тюрк. talpin- 'биться', 'трепыхаться' [Топоров 1975: 44].

Рус. телепень, телепать рассматриваются В.Н. Топоровым как отражение одной из ступеней морфонологического ряда праслав. *telp-/*talp-/*tlp- [Топоров 1975: 13]. При таком объяснении с формальной точки зрения в стороне остаются отступления от закономерного развития группы telp- по типу *melti $>$ молоть, *melko > молоко на вост.-слав. почве. Следует заметить, что преобразование *telp$>$ *telep-, выпадающее из общей линии развития, не получило удовлетворительного объяснения. Как показывает материал, развитие *telp- > *telep-, *telop- наблюдается после шипящей согласной в русском языке в ele, elo: cp. *čelnъ > укр. челен, *želbъ > pус. жёлоб и т.п [Мейе 1951: 57]. А. А. Шахматов полагал, что сочетание et с долгим сонантом перешло в еле перед $e$ и тем $b$, которое изменилось впоследствии в $e$, т. е. telt $>$ telet, в дальнейшем *telet было вытеснено *tolot, а перед следующим $u$ перешло в или, ср. тилизну́ть (Шахматов 1902: 360-361). Отмечается и возможность влияния других факторов, поскольку слово функционирует в системе определенных парадигматических и семантических отношений и испытывает влияние и притяжение со стороны родственных образований, как в случае половня $>$ пелевня под влиянием пель, пелъве 'мякина' [Шахматов 1915: № 245, 153].

Далее предполагается, что унаследованный древний термин пчеловодства, являясь частью морфонологического ряда *telp-/*talp-/ *tlp-, связан чередованием корневого вокализма с продолжениями слав. *tъlpa / *tblpa (> pyc. толna, ср. в песне пчелы толиятся, телепаются), в котором совмещаются оба значения, предполагаемые для исходной основы, - 'беспорядочное движение' и 'нечто больших размеров, сбитое в одну большую массу'. Ближайшие соответствия находят в балтийских языках — лит. til̃pti (telpù) 'занимать определенное место', 'помещать, поместить', 'вмещать', talpà 'емкость, объем', лтш. tilpt, tęlpu 'помещаться, входить, доходить', talpa 'помещение', далее др.-инд. tálpas, talpa '‘ложе, седалище', ирл. tallaim 'нахожу место' и под. [Brückner 572; Фасмер IV: 74; Топоров 1975: 13]. В словаре Покорного к продолжениям и.-е. *telp- 'пространство' отнесено тох. A tsälp- 'идти, переходить (на другую сторону), становиться спасенным, избавленным’ [Pokorny I: 1062].

Однако остается много неясного в характере отношений вост.-слав. и литовских образований. Традиционно в соотношении слав. *tъlpa лит. tilpti принимается за исходное значение, зафиксированное в литовском языке, - 'занимать место, 
помещать', но при этом не учитывается, что литовский язык как один из многих и.-е. языков может иметь свою независимую линию семантического развития, и потому в семантике литовского слова необязательно видеть отражение хронологически более раннего состояния. Семантика образует довольно сложную систему, структура и наполнение которой определяется многими факторами. Значения, рассеянные по славянским диалектам, отражают лишь возможности семантических преобразований в рамках одного гнезда родственных слов. Движение внутри значения, изменение его объема происходит индивидуально в рамках одной языковой системы. Нет прямых мотивационных связей между конкретным значением, засвидетельствованным в какой-то части славянского ареала, и тем значением, которое отмечено в языковой системе другого ареала. Можно лишь говорить о потенциальных возможностях преобразований значения, принимаемого за исходное. В основе семантических изменений лежат более сложные процессы. Применительно к рассматриваемому нами случаю В.Н. Топоров полагает, что развитие семантики определялось не конкретными значениями, здесь действовали механизмы более общего плана, основанные на соотношении объема и его заполнения, категорий неодушевленности, статичности, динамичности [Топоров 1975: 14]. Воплощением неких общих образов, определивших преобразования семантики в том или другом направлении, стали засвидетельствованные в славянских языках конкретные значения, на основе которых складывалась своя система семантических отношений, свои мотивационные отношения.

Пониманию семантических возможностей вост.-слав. образований и слав. *tblpa способствует принимаемое некоторыми исследователями [Brückner 572] сближение с польск. диал. кауз. ttopić 'давить, толкать, вдавливать, втискивать, нагнетать', диал. tłopić pole 'оставлять поле под паром', tłopić się, tłopaczyć się 'с силой пихаться, толкаться, проталкиваться’ [Warsz. VII, 66] с реконструкцией исходной формы *tolpiti, имеющей структуру производного регулярного типа от не засвидетельствованного в славянских языках гл. **telpti с предполагаемым для него значением 'бить, колотить, толочь'. Я. Отрембский, поддерживая идею сближения слав. *tzlpa и приведенных польских глаголов, отмечает, что согласно исторической фонетике польского языка ожидалась бы форма гл. *ttupić się (cp. stup 'столб' < *stlp- < и.-е. *stel-p-) [Boryś 560], но такое отступление, как он полагает, стало возможным по причине влияния гл. tłoczyć się, а также tłok [Otrębski 1948: 353/107]. Однако необходимо принять во внимание и то обстоятельство, что польск. tłopic непосредственно не связано отношением производности с *tzlpa, а представляет собой отражение ступени *tolp- в морфонологическом ряду *telp-/*tolp-/ *tlp-.

Славянский материал позволяет расширить круг продолжений слав. *tolpи включить в этот ряд болгарские образования: ср. тла́nам, тлапу́вам 'бредить', тлапнґ́ v 'худая молва' [Геров 5: 338-339], натла́nґиь 'навязываться', натлапювася въ ума, въ память-тж 'врезываться в память', натла́nа. натла́nъ 'то, что врезается в память' (Геров 1: 174; 3: 230), втлап п, втлапгаvвамь 'натверживать', 'вперить глаза', ботевгр. на̀тлап 'навязчивый, назойливый человек' [Илчев БД I: 196], ‘человек, который ходит в гости без приглашения', ‘животное ожесточенное, 
разъяренное', на́тлапа 'настойчивый, навязчивый’, к на́тлапя и т. п. [БЕР 4: 554], mла́nамь ‘бредить' [Геров 5: 338], софийск. тла̀nи ми се 'чудится мне, что кто-то скоро умрет’ [Божкова БД I: 269], тлапѝм 'бредить' [Гълъбов БД II: 108], родоп. тлапо̀вам 'говорить во сне, бредить' [Стойков БД V: 212 и др.: см. БЕР 8: 69-70]. Семантика болгарских образований в общем виде сводится к двум основным значениям - 'давить', отсюда 'вперить взгляд', 'настойчивый; назойливый, навязчивый’ и 'бредить', отсюда 'мечтать, грезить', 'видеть во сне'. К продолжениям той же основы можно отнести с.-хорв. диал. утла́пи 'грубо, силой сунуть что-л. в руку', утла́пи се 'прийти без приглашения' [Динић 2008: 869]. Семантическая эволюция не образует прямой линии с последовательной взаимосвязью и мотивацией значений, но признаки исходной семантики уже в преобразованном виде продолжают жить, они проявляются в семантике отдельных образований, как в случае болгарских лексем со значением 'грезить, мечтать и т.п.', в плане семантики ср. родственные гл. *bresti, bredo pус. бредить бред [ЭССЯ 3: 12-13].

Особо стоит вопрос о характере отношений приведенных образований со ст.слав. въстмапнти 'укротить, смирить’ [Ст.-слав. сл. 155: Супр.], форма без префик-

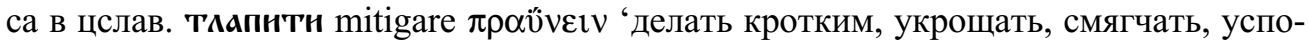
каивать' [Mikl. LP 991]. Эти слова отнесены к числу неясных в ESJS [18: 1109]. В словаре Брюкнера этот глагол и с.-хорв. tlapiti 'болтать' выводятся из *tolp[Brückner 572], А. Вайан определяет ст.-слав. глагол как фактитив, соотносительный c *tzlpa, и полагает, что в меньшей степени это относится к чеш. roztlapiti 'растоптать', которое ближе к tlapa 'лапа' [Vaillant III: 421] и, по мысли Махека, происходит из lapa [Machek 645], и еще меньше к с.-хорв. tlápiti = klápiti (с переходом $t l>$ $k l)$ 'грезить, мечтать', 'видеть во сне' (ср. сву ноћ сам тлапно којешта - somnio susdeque), ср. производное от него на -nja - tlapnja 'somnia promiscua', 'болтовня' [Вук 1898: 765]. В некоторых источниках ст.-слав. глагол соотносится с гот. plaqus mollis и далее с *(u)toliti, тот же вывод распространяется и на с.-хорв. слово [Mikl. 357; Skok III: 477] и др. Трудно провести разграничение звукоподражаний и полноценных слов, претерпевших глубокие изменения в семантике. Можно думать, что одна из причин затруднений в понимании внутренней формы ст.-слав. въсткапнтн 'укротить, усмирить' связана с описанием значения глагола. Приведенный в словаре пример на употребление глагола в Супрасльской рукописи въстмапнвъ гнЊвъ сковесы крот"ъкымн позволяет думать, что в определении значения иносказательно передается изначально заложенный в нем смысл — 'подавить (гнев)', отсюда 'укротить, усмирить' [Ст.-слав. сл. 155]. Другая причина — в словах, передающих характер действия стирается изначальный признак, который проявляется лишь в контексте. И это дает право отнести ст.-слав. глагол к рассматриваемому нами гнезду слов.

В русских диалектах существует еще одна группа слов, изучение которой позволяет в предположительной форме поставить вопрос о возможном родстве рус. mелеna $<*$ tolp- с образованием, которое отнесено в литературе к числу неясных. Таким образованием является диал. (том.) то́лоп и толопа́ в значении 'тропа, звериная тропа’ [СРНГ 44: 204]. Изолированный диалектизм засвидетельствован на территории, где русские говоры находятся в окружении местных языков и диалектов, 
что и стало основанием для предположения о заимствовании: Хелимский называет источником селькупские диалекты, но конкретный источник заимствования остается неясным [Аникин 2000: 551]. Объяснение истоков слова в самом общем виде, без достаточного обоснования, только исходя из ареальной ограниченности и обособленного положения в словаре, оставляет много вопросов и потому побуждает продолжить поиски решения, но уже на других основаниях с учетом структуры слова, возможных для него внутриславянских связей, понимания природы этимологического гнезда.

С расширением материала в составе славянской лексики открываются факты, позволяющие преодолеть изолированность русского диалектизма и продвинуться в понимании истоков рус. диал. толопа. В контексте восстанавливаемых связей допустимо видеть в диал. толопа именное образование с вокализмом $о$, сложившееся на основе гл. **telpti. Следует отметить, что в русских говорах европейской части представлена лексема со сходным значением, но с отличием в оформлении исхода слова - толоба́ 'звериная тропа' (смол.), 'узкая тропинка по снегу, грязи' (ворон.) [СРНГ 44: 198], с этой лексемой, несомненно, связан отыменный гл. затоло́бить 'затоптать' (смол.) [СРНГ 11: 97]. Это слово, как и толоп, стоит особняком в словаре. Исходным для толоба мог стать гл. *telbti < $(* t e l-b-$, cp. *tel-k-ti), частично слившийся с упомянутыми выше образованиями типа телебать. Возможно, появление параллельной формы на -оба вызвано сближением и притяжением по формальным и семантическим основаниям со стороны близкого наименования *dolbb/*dolba, производного от гл. *delbti [ЭССЯ 5: 59-60]. Диалектизмы толопа, толоба подчиняются словообразовательно-семантической модели образований названий дорог и тропинок в славянских языках (ср. *torb 'проторенная дорога' *terti, tbro, *prosěka 'прорубленная дорога' *sěkt’i, *dorga *dbrgati и т. п.) [Куркина 1968: 92-105].

Как видим, гнездо слав. *tel-p-, унаследованное из и.-е. праязыка, сохранилось в виде отдельных фрагментов, рассеянных по славянской территории. Восстановление разрушенных исходных генетических связей основано на закономерностях структурных отношений основ и углубленного изучения семантики, функционирования слов в разных понятийных контекстах.

\section{Литература}

Аникин 2000 - Аникин A. E. Этимологический словарь русских диалектов Сибири. Заимствования из уральских, алтайских и палеоазиатских языков. 2-е изд., испавленное и дополненное. М.-Новосибирск: «Наука», 2000.

Балецкий - Балецкий Э. Из словарного состава карпатских (украинских) говоров // Studia slavica. Academiae Scientiarum Hungaricae. Redigit St. Kniezsa. T. IV, fasc. 1-2. Budapest, 1959, 181-192.

БЕР - Български етимологичен речник. Т. 1-8-. София: Издателство на Българската Академия на науките / Академично издателство «Проф. Марин Дринов», 1971-2017-. 
Блр.-рус. - Беларуска-рускі слоўнік. Пад. рэдакцыяй акад. АН БССР К.К. Крапівы. М.: Государственное издательство иностранных и национальных словарей, 1952.

Божкова // БД I - Божкова 3. Принос към софийския говор // БД І. С.: АН Болгарии. Институт болгарского языка, 1962.

Вук 1898 - Вук Караџић. Српски рјечник. Истумачен њемачкијем и латинскијем ријечима. Скупио га и на свијем издао Вук Стеф. Караџић. 3-е изд. Белград, 1898.

Гамкрелидзе, Иванов - Гамкрелидзе Т. В., Иванов Вяч. Вс. Индоевропейский язык и индоевропейцы. Реконструкция и историко-типологический анализ праязыка и протокультуры. Тбилиси: изд. Тбилисского университета, 1984.

Геров - Геров Н. Речник на българския език. Т. 1-6. София: Български писател, 1975-1978.

Горяев - Горяев Н. Этимологический словарь русского языка. 2-е изд. Тифлис, 1896.

Гринченко - Гринченко Б. Д. Словарь украинского языка. Т. 1-4, Киев, 19071909.

Гълъбов // БД ІІ - Гъльбов Л. Говорът на с. Доброславци, Софийско // БД ІІ. С.: АН Болгарии. Институт болгарского языка, 1965.

Даль ${ }^{2}$ - Даль В.И. Толковый словарь живого великорусского языка. Т. 1-4 (1863-1866), набрано и напечатано со второго издания 1880-1882 гг., Москва, 1955.

Динић 2008 - Динић J. Тимочки дијалекатски речник. Институт за српски језик САНУ. Монографије 4. Београд, 2008.

ЕСУМ - Етимологічний словник української мови / Ред. кол.: О.С. Мельничук, І. К. Білодід, В. Т. Коломіець, Т.Б. Лукінова, Г.П. Півторак, В.Г. Скляренко, О.Б. Ткаченко. Т. 1-6. К., 1982-2012.

Илчев // БД I - Илчев Cm. Към ботевградската лексика // БД І. С.: АН Болгарии. Институт болгарского языка, 1962.

Куркина 1968 - Куркина Л. В. Из наблюдений над некоторыми названиями дорог и тропинок в славянских языках // Этимология 1968. М.: Наука, 1971.

Мейе 1951 - Мейе A. Общеславянский язык. Перевод с второго франц. издания. М.: изд. Иностранной литературы, 1951.

РСКНЈ — Речник српскохрватског књижевног и народног језика. Књ. VI. Институт за српскохрватски језик. Београд, 1969.

СД - Славянские древности. Т. I-VI. М.: Международные отношения, 19952012.

СРНГ - Словарь русских народных говоров. Ред. В. П. Филин, Ф. П. Сороколетов, С. А. Мызников. Вып. 1- 46-. Л., СПб.: Наука, 1965-2013-.

Стойков // БД V - Стойков T. Родопски речник // БД V.C.: АН Болгарии. Институт болгарского языка, 1970.

Ст.-слав. словарь - Старославянский словарь (по рукописям X-XI веков). Под редакцией Р. М. Цейтлин, Р. Вечерки и Э. Благовой. М.: Русский язык, 1994. 
Топоров 1972 - Tопоров B. H. *Tel-p-n-, *tal-p-n- в свете ностратической перспективы // Конференция по сравнительно-исторической грамматике индоевропейских языков (12-14 декабря). Предварительные материалы. М.: Наука, 1972, $78-81$.

Топоров 1975 - Топоров В. Н. К объяснению некоторых славянских слов мифологического характера в связи с возможными древними ближневосточными параллелями // Славянское и балканское языкознание. Проблемы интерференции и языковых контактов. М.: Наука, 1975, 3-49.

Фасмер - Фасмер М. Этимологический словарь русского языка. Перевод с нем. и дополнения О.Н. Трубачёва. М.: Прогресс, 1964-1973.

Шахматов 1902 - Шахматов А.А. К истории звуков русского языка. Замена долгих плавных слоговыми // Изв. ОРЯС т. VII, кн. 2. СПб., 1902, 303-382.

Шахматов 1915 - Шахматов А.А. Очерки древнейшего периода истории русского языка. Изд. 3-е, стереотипное с изд. 1915 г. М., 2016.

ЭССЯ - Этимологический словарь славянских языков. Праславянский лексический фонд. Вып. 1-41-. Отв. ред. акад. О. Н. Трубачёв, д.ф.н. А. Ф. Журавлев. М.: Наука, 1974-2018.

Bernard 1960 - Bernard R. Étude de quelques mots du dialecte de Razlog d'après le t. XLVIII du Cб. за народни умотворения и народопис // Езиковедско-етнографски изследвания в памет на ак. Т. Романски, С., 1960 368-369.

Bezlaj - Bezlaj F. Etimološki slovar slovenskega jezika. Vol. I-V. Ljubljana, 19762007.

Boryś - Boryś $W$. Słownik etymologiczny języka polskiego. Kraków: Wydawnictwo literackie, 2005.

Brückner - Brückner A. Słownik etymologiczny języka polskiego. Kraków: Krakowska Spólka wydawnicza, 1927.

ESJS - Etymologický slovník jazyka staroslověnského. Seš. 1-16-. Hl. red. E. Havlová, A. Erhart, I. Janyšková. Praha: ACADEMIA. Nakladatelství Akademie věd České Republiky, 1989-2012-.

Fraenkel - Fraenkel E. Litauisches etymologisches Wörterbuch. T. I-II. Heidelberg, $1955-1965$.

Kott - Kott F. Česko-německý slovník. D. I-VII. Praha: Kolár, 1878-1893.

Machek — Machek V. Etymologický slovník jazyka českého. Praha, 1997.

Mikl. - Miklosich F. Etymologisches Wörterbuch der slavischen Sprachen. Wien, 1886.

Mikl. LP - Miklosich F. Lexicon Palaeoslovenico-Graeco-Latinum. Vindobonae, 1862-1865.

Otrębski - Otrębski J. Życie wyrazów w języku polskim. Prace Komisji filologicznej, tom XII, zeszyt 2. Poznań, 1948.

Plet. — Pleteršnik M. Slovensko-nemški slovar. Vol. T. I-II. Ljubljana, 2006.

Pokorny - Pokorny J. Indogermanisches etymologisches Wörterbuch. Bd. I-II. Bern, 1959-1969. 
RJA - Rječnik hrvatskoga ili srpskoga jezika. Vol. I-XV. Zagreb, 1880-1976.

SJS - Slovník jazyka staroslověnského. Lexicon linguae palaeoslovenicae = Словарь старославянского языка. Т. I-IV. СПб., 2006.

Skok — Skok P. Etimologijski rječnik hrvatskoga ili srpskoga jezika. Knj. I-IV. Zagreb: Jugoslavenska akademija znanosti i umjetnosti, 1971-1974.

Vaillant III - Vaillant A. Grammaire comparée des langues slaves. T. III. Le verbe. Deuxième partie. Paris, 1966.

Warsz. — Karłowicz J., Kryński A., Niedźwiedzki W. Słownik języka polskiego, t. IVIII, wyd. fotooffsetowe. Warszawa, 1952.

\section{V. Kurkina}

Vinogradov Russian Language Institute of the Russian Academy of Sciences

(Moscow, Russia)

lyukurkina@rambler.ru

\section{RECONSTRUCTING THE *TELP- WORD FAMILY}

The paper presents an attempt at recovering genetic ties between lexical entities with the root *telp- scattered across Slavic languages. The starting point for research were Russ. dial. телепать and телепень, that, according to V.N. Toporov, reflect one of the grades in a morphonological series *telp- : *tolp- : *tъlp- (here belong hitt. Telepinuš 'god of fertility', luv. taluppi 'lump') with original semantic value 'chaotic, erratic movement' and 'something lumped together'. Arguments are proposed in favor of linking Russ. dial. *tzlpa to Pol. ttopić się 'to crowd, push' on formal and semantic grounds. A hypothetical question is posed as to whether Russ. dial. толопа 'animal path', otherwise believed to be a borrowing, could also belong to this group.

Key words: etymology, morphonological relations, structure, reconstruction of semantics.

\section{References}

Anikin A. Etimologicheskii slovar' russkih dialektov Sibiri. Zaimstvovania iz uralskih, altajskih i paleoasiatskih jazykov [Etymological dictionary of Russian dialects of Siberia. Borrowings from Uralic, Altaic and Paleoasiatic languages]. Moscow-Novosibirsk: Nauka Publ., 2000 (in Russ.).

Baleckij E. Iz slovarnogo sostava karpatskih (ukrainskih) govorov [From the vocabulary of the Carpathian (Ukrainian) dialects]. Studia Slavica IV, fasc. 1-2. Budapest, 1959 (in Russ.).

Belaruski-russki slovar' [Belarusian-Russian dictionary]. Moscow, 1952 (in Russ.).

Bezlaj F. Etimološki slovar slovenskega jezika [Etymological Dictionary of Slovenian Language]. Vol. I-V. Ljubljana, 1976-2007 (in Slov.). 
Boryś W. Stownik etymologiczny języka polskiego [Etymological dictionary of the Polish language]. Kraków, 2005 (in Polish).

Bozhkova E. Prinos k sofijskia govor [The question of the dialect of Sofia.]. Bulgarian dialectology I. Sofia: Academy of Sciences of Bulgaria. Institute of Bulgarian language, 1962 (in Bulg.).

Brückner A. Stownik etymologiczny języka polskiego [Etymological dictionary of the Polish language]. Kraków, 1927 (in Polish).

By̆lgarski etimologichen rechnik [Bulgarian Etymological Dictionary]. Vol. 1-8-. Sofia: Bulgarian Academy of Sciences / Academic Publisher «Prof. Marin Drinov» Publ., 1971-2017- (in Bulg.).

Dal' V.I. Tolkovyj slovar' zhyvogo velikorusskogo jazyka [Explanatory Dictionary of the Russian Language]. Vol. I-IV, Saint Petersburg; Moscow, 1880-1882 (in Russ.).

Dictionary of Old Church Slavonic language (based on manuscripts of 10th-11th centuries). Edited by R. M. Cejtlin, R. Veczerka and E. Blahova. Moscow: Russian language Publ., 1994 (in Russ., Greek, Lat.).

Dinich J. Timochki dijalekatski rechnik [Dictionary of the Timok dialect]. Beograd, 2008.

Etimologicheskii slovar' slav'anskih jazykov. Praslav'anskii leksicheskii fond. [Etymological Dictionary of the Slavic Languages. Proto-Slavic Lexical Stock]. Vols. 1-41-. Moscow: Nauka Publ., 1974-2018-(in Russ.).

Etimologiczeskii slovar' ukrainskogo slovar'a [Etymological Dictionary of Ukrainan Language. Vol. 1-7-. Kiev: 1982-2012 (in Ukr.).

Etymologický slovník jazyka staroslověnského [Etymological Dictionary of Old Church Slavonic Language]. Seš. 1-16-. Praha, 1989-2012-(In Czech).

Gerov N. Slovar' by̆lgarskogo jazyka [A Dictionary of Bulgarian Language]. Vol. 1-6. Sofia: Bulgarian Writer Publ., 1975-1978 (in Bulg.).

Goriaev N. Etimologicheskii slovar' russkogo jazyka [Etymological Dictionary of Russian Language]. Tiflis, 1896 (in Russ.).

Gy̆ly̆bov I. Govor sela Dobroslavci, Sofijsko [The dialect of the village Dobroslavci, Sofijsko]. Bulgarian dialectology II. Sofia: Bulgarian dialectology I. Sofia: Academy of Sciences of Bulgaria. Institute of Bulgarian language, 1965 (in Bulg.).

Fasmer M. Etimologicheskii slovar' russkogo jazyka [Etymological Dictionary of the Russian language]. Vols. I-IV. Moscow: Progress Publ., 1964-1973 (in Russ.).

Ilczev St. K botevgradske leksike [On Botevgrad Dialectal Vocabulary]. Bulgarian dialectology I. Sofia: Bulgarian dialectology I. Sofia: Academy of Sciences of Bulgaria. Institute of Bulgarian language, 1962 (in Bulg.).

Ivanov Vjach., Gamkrelidze T. Indoevropeiskii jezik i indoevropeicy [Indo-European and the Indo-Europeans. A reconstruction and a historical-typological analysis of a protolanguage and a proto-culture]. Vols. I-II. Tbilisi, 1984.

Kott F. Česko-německý slovník [A Czech-German Dictionary]. D. I-VII. Praha: Kolár Publ., 1878-1893 (in Czech).

Kurkina L.V. Iz nabl'udenij nad nekotorymi nazvanijami dorog $i$ tropinok $v$ slavjanskih jazykah [From observations on some names of roads and footpaths in Slavic languages]. Etymology 1968. M.: Nauka Publ., 1971 (in Russ.). 
Machek V. Etymologický slovník jazyka českého [Etymological Dictionary of the Czech Language]. Praha, 1997 (in Czech).

Meillet A. Obszczeslavjanskii jazyk [The Common Slavic Language]. Translated from the second French edition. Moscow: Publishing House of Foreign Literature, 1951 (in Russ.).

Miklosich F. Etymologisches Wörterbuch der slavischen Sprachen [Etymological Dictionary of the Slavic Languages]. Wien, 1886 (in Germ.).

Miklosich F. Lexicon Palaeoslovenico-Graeco-Latinum [Old Slavic — Greek — Latin lexicon]. Vindobonae, 1862-1865 (in Germ., Greek, Lat.).

Otrębski J. Zhycie wyrazow w jezyku polskim [The life of words in the Polish language]. Poznań, 1948 (in Polish).

Pleteršnik M. Slovensko-nemški slovar [Slovenian-German Dictionary]. Vol. T. I-II. Ljubljana: 2006 (In Slov. and Germ.).

Pokorny J. Indogermanisches etymologisches Wörtebuch [Indo-European Etymological Dictionary]. Vol. I-II. Bern, 1959-1969 (in Germ.).

Rečnik srpskohrvatskog književnog i narodnog jezika [Dictionary of the Serbo-Croatian literary and popular language]. Beograd, 1969 (in Serb.).

Rječnik hrvatskoga ili srpskoga jezika [Dictionary of Croatian, or Serbian, Language]. Vol. I-XV. Zagreb, 1880-1976 (in Serb.).

Schachmatov A. A. Istoria zvukov russkogo jazyka. Zamena dolgih plavnyh slogovy$m i$ [The History of the Sounds of the Russian Language. Substitution of Long Liquids for Syllabic Resonants]. News ORJS, vol. VII/2. SPb., 1902 (in Russ.).

Schachmatov A. A. Oczerki drevnejszego perioda istorii russkogo jazyka [Essays on the Earliest Period of History of the Russian Language]. $3^{\text {rd }}$ stereotypical edition, from the edition of 1915 (in Russ.).

Skok P. Etimologijski rječnik hrvatskoga ili srpskoga jezika [Etymological dictionary of Croatian or Serbian language]. Knj. I-IV. Zagreb: Jugoslavenska akademija znanosti i umjetnosti, 1971-1974 (in Serb.).

Slovar' russkih narodnyh govorov [Dictionary of Russian Dialects]. Iss. 1-46-. Leningrad-Saint Petersburg: Nauka Publ., 1965-2013- (in Russ.).

Slavianskie drevnosti [Slavic Antiquities]. Vol. I-VI. Moscow: International Relations Publ., 1995-2012 (in Russ.).

Slovník jazyka staroslověnského. Lexicon linguae Palaeoslovenicae = Slovar' staroslavjankogo jazyka. [A Dictionary of Old Church Slavic Language]. Vol. I-IV. S.-Peterburg, 2006 (In Czech, Greek, Lat.).

Slavianskie drevnosti [Slavic antiquity]. Vol. I-VI. Moscow: International Relations Publ., 1995-2012 (in Russ.).

Słownikjęzyka polskiego [A Dictionary of Polish Language]. Vol. I-VIII. Warszawa, 1952 (In Polish).

Stojkov T. Rodopski rečnik [Dictionary of Rodop]. Bulgarian dialectology V. Sofia: Bulgarian dialectology I. Sofia: Bulgarian Academy of Sciences. Institute of Bulgarian language, 1970 (in Bulg.).

Vuk Karadžić. Srpski rječnik. [Serbian Dictionary]. Belgrad, 1898. 